\title{
Bioactives and extracts affect the physico- chemical properties of concentrated whey protein isolate dispersions
}

\author{
Mackenzie M. Hansen ${ }^{1,2^{*}}$ (D, Richard W. Hartel ${ }^{2}$ and Yrjö H. Roos ${ }^{1}$
}

\begin{abstract}
Non-covalent complexation interactions are known to occur between bioactive compounds and proteins. While formulating with these components can have positive outcomes such as stabilization of colors and actives, it can also result in changes to the structures and physical properties of proteins, affecting product functionality and sensory attributes. Previous experiments reported measurable changes in the physico-chemical properties of whey protein isolate (WPI) dispersions upon formulation with Aronia berry extract, ascribing changes to proteinpolyphenol (PP) interactions in the systems. Pure gallotannin, beet extract, and cranberry extract, providing a diverse variety structures and sizes, were selected for further experimentation and comparison with the effects of Aronia extract. Concentrated dispersions with varying WPI:sucrose ratios, formulated with several bioactives contents from multiple different sources were analyzed to identify the effects of different bioactives on physicochemical properties of dispersions. Dispersions formulated with cranberry extract demonstrated the largest increases in surface tensions, viscosities, and particle sizes, while those formulated with beet extract were the least affected by the presence of bioactives, suggesting that different bioactives and extracts had varying propensities for complexation interactions with WPI, despite their relatively low levels of addition (0, 0.5 , and $1 \%)$.
\end{abstract}

Keywords: Whey protein, Concentrated dispersions, Polyphenols, Extracts, Physico-chemical properties

\footnotetext{
* Correspondence: 116220787@umail.ucc.ie

${ }^{1}$ Food Technology, School of Food and Nutritional Sciences, University College Cork, Cork, Ireland

2Department of Food Science, College of Agricultural and Life Sciences, University of Wisconsin, Office A11, Babcock Hall, 1605 Linden Drive, Madison, WI 53706, USA
}

(c) The Author(s). 2022 Open Access This article is licensed under a Creative Commons Attribution 4.0 International License, which permits use, sharing, adaptation, distribution and reproduction in any medium or format, as long as you give appropriate credit to the original author(s) and the source, provide a link to the Creative Commons licence, and indicate if changes were made. The images or other third party material in this article are included in the article's Creative Commons licence, unless indicated otherwise in a credit line to the material. If material is not included in the article's Creative Commons licence and your intended use is not permitted by statutory regulation or exceeds the permitted use, you will need to obtain permission directly from the copyright holder. To view a copy of this licence, visit http://creativecommons.org/licenses/by/4.0/. 


\section{Graphical Abstract}

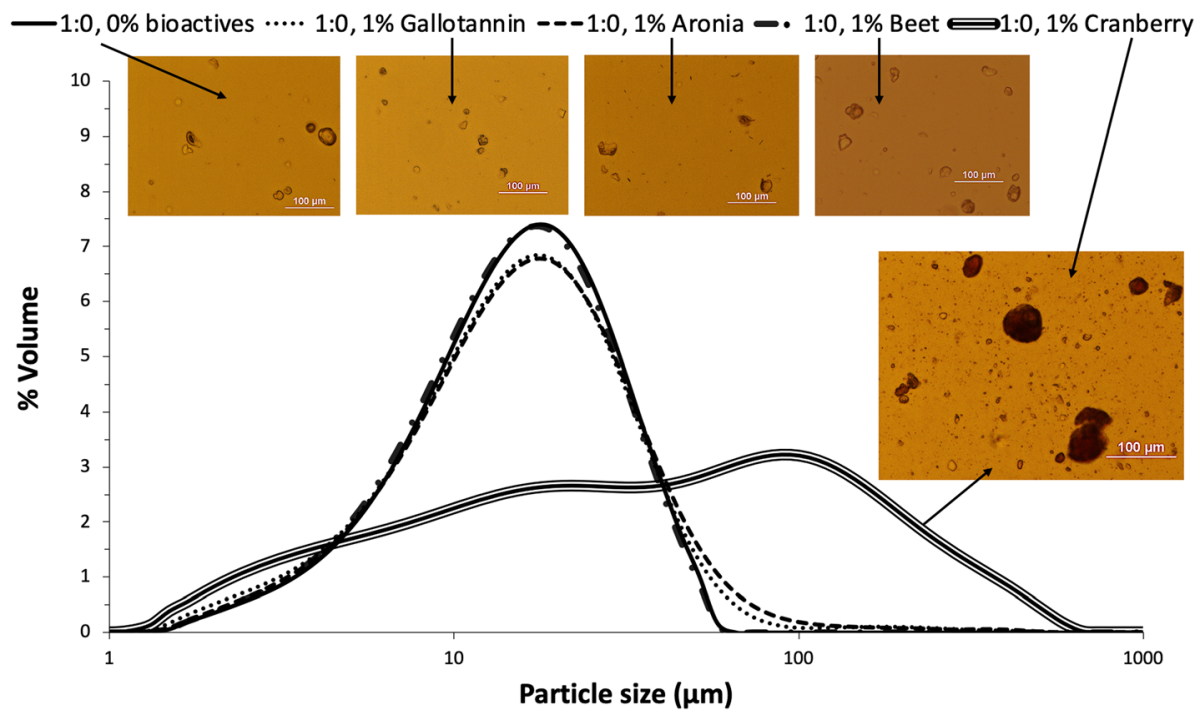

\section{Introduction}

Consumer interest is often a catalyst for the development of new and improved products in the food industry. Increased demand for health-supporting and functional products has driven the development of high protein foods with bioactives and other nutrients from fruits and vegetables due to the perceived benefits of consuming naturally-derived, bioactive compounds that are thought to positively affect human health (Kapsak et al. 2011; Banovic et al. 2018; Calderón-Oliver \& Ponce-Alquicira 2017; González 2020; Hansen et al. 2021a, b). In addition to the demand for healthy foods, consumers have pushed developers to replace synthetic colorants in foods with naturally derived color compounds (Sigurdson et al. 2017). Fruits and vegetables are an attractive source of natural pigments that may also provide health benefits when formulated into food products (Calderón-Oliver \& Ponce-Alquicira 2017; Akbar Hussain et al. 2018; de Mejia et al. 2020), though natural color compounds, like polyphenols (PP) and betalains, are known to have low chemical stability in foods during storage (Miguel 2018; de Mejia et al. 2020; Hansen et al. 2021a, b).

Polyphenols are a family of compounds ubiquitous in fruits and vegetables reported to have strong antioxidant properties, are most commonly found as glycosides with sugar units on the polyphenol structures, and can be divided into monomeric and polymeric PP categories (Tsao 2010; Hansen et al. 2021a, b). Monomeric PP, such as phenolic acids and flavonoids, are relatively small compounds; anthocyanins are a common flavonoid varying in color from orange to purple, and are the primary bioactive pigment compounds found in Aronia berries (Dabas 2016; Xie et al. 2016, 2017). Polymeric PP are larger compounds with greater molecular masses and can be categorized as condensed or hydrolysable tannins. Condensed tannins are more abundant in the human diet and include proanthocyanidins, the main bioactive pigment compounds lending the red-purple color to cranberries and other fruits and vegetables (Oliveira et al. 2013). Hydrolysable tannins such as gallotannin, while less common in the human diet, can be found in almonds and mango peel (Girard \& Awika 2020). Betalains, while relatively small and water-soluble, are nitrogenous and not chemically or structurally related to anthocyanins. They can be divided into betaxanthins and betacyanins, including betanin, the main bioactive compound imparting the deep red-violet color in beets (Miguel 2018; de Mejia et al. 2020).

Polyphenols and betalains have been reported to possess innate abilities to complex with proteins in neutral and acidic $\mathrm{pH}$ formulations primarily via weak, noncovalent hydrophobic interactions and hydrogen bonds to varying extents, depending on the compound (Gad \& El-Salam 2010; Schneider 2016; Girard \& Awika 2020; Zhao et al. 2020; Hansen et al. 2021a, b). When considering polymeric PP such as gallotannin and proanthocyanidins, structural characteristics including higher degrees of polymerization, larger molecular sizes, more conformational flexibility, and larger numbers of hydroxyl groups and hydrophobic regions available may be indicative of greater volumes and strength of protein-PP interactions (Hagerman 1989; Harbertson et al. 2014; 
Ropiak et al. 2017; Girard \& Awika 2020; de Mejia et al. 2020). Girard et al. (2019) reported that the affinity of condensed tannins for gluten protein interactions was greater than that of hydrolysable tannins likely due to the enhanced conformational flexibility of condensed tannins. Although the interaction affinity between anthocyanins and proteins may be more limited due to the relatively small size of the flavonoids compared to polymerized PP and lower relative quantities of hydrophobic regions and hydroxyl groups present, in previous experiments measurable changes in the physical properties of protein dispersions with anthocyanin-rich Aronia berry extract addition were observed, indicative of some extent of protein-PP interaction (Girard \& Awika 2020; de Mejia et al. 2020; Hansen et al. 2021a, b, c). Despite the relatively small molecular structures compared to polymerized PP, betalains are larger than anthocyanins and have been reported to have some affinity for protein interactions, likely due to the presence of few hydroxyl groups and hydrophobic regions present and available (Martínez et al. 2019; de Mejia et al. 2020; Zhao et al. 2020). Complexation interactions between proteins and bioactive compounds including PP and betalains are known to affect protein structures and hydrodynamic volumes in dispersions (Rawel et al. 2005; Martínez et al. 2019; Sęczyk et al. 2019; Zhao et al. 2020), as well as physico-chemical, functional and nutritional properties of the products (Girard et al. 2016; Hansen et al. 2021a, b; Li et al. 2021; Sharma et al. 2021). Additionally, conjugation interactions may be useful for bioactives protection and delivery as well as color retention (Cao \& Xiong 2017; Ma \& Zhao 2019; Quan et al. 2019; Zhao et al. 2020; Baba et al. 2021).

The objective of this study is to investigate the extent of interactions between whey protein isolate (WPI) and bioactive compounds from various sources, indicated by measurable changes in the physical properties of concentrated, liquid feed dispersions with varied formulations, including flow properties, viscosity, particle size distribution, $\mathrm{pH}$, centrifuge separation, and microstructure imaging. Bioactives sources including pure gallotannin and Aronia berry, beet, and cranberry extracts were selected for their health-promoting properties and variety of predominant compounds with diverse molecular structures and sizes for comparison. Extracts known to have predominantly larger-sized bioactive compounds with higher flexibility and degrees of polymerization and more hydroxyl groups and hydrophobic regions (such as cranberry extract or gallotannin), would be expected to interact with proteins more extensively than extracts delivering smaller-sized bioactive compounds with fewer potential sites for interactions (such as Aronia and beet extracts) in the same concentration in dispersions (de Mejia et al. 2020; Girard \& Awika 2020). More extensive protein-bioactive interactions may result in greater changes in the physical properties of dispersions measured such as viscosity, particle size distribution, flow properties, etc., compared to formulations containing actives with lower propensities for interactions with proteins. This work furthers previous experimental findings, providing additional information regarding the effects of different bioactive compound addition to the physicochemical properties of concentrated whey protein dispersions, and the potential for non-covalent proteinbioactive interactions. We presented multiple processes for producing dry, stable beads intended for the encapsulation of bioactives from concentrated WPI-sucrose dispersions in earlier experiments (Hansen et al. 2020, 2021c). This study focuses on alterations of the physicochemical properties of the dispersions intended for bead formation as different bioactives are added to mixtures and subsequent interactions occur between matrix components. These findings might inform developer's decisions regarding the addition of even small amounts of natural extracts as colorants or sources of bioactives to protein-containing food matrices, as sensory properties could be jeopardized with changes in the physical properties of products.

\section{Materials and methods Materials}

IsoChill 9000 WPI was provided by Agropur, Inc. (Luxemburg, WI, USA), comprised of approximately 91.6\% protein (dry basis), $4.6 \%$ water, $0.7 \%$ fat, and $3.1 \%$ ash. Extra fine, granulated, pure can sucrose was obtained from Domino Foods, Inc. (Yonkers, NY, USA). Pure gallotannin in crystalline solid form ( $\geq$ 98\% purity) was purchased from Cayman Chemical Company (Ann Arbor, MI, USA). Standardized Aronia berry (chokeberry) powder comprised of $55.6 \%$ total PP and a minimum of $15 \%$ anthocyanins, and Standardized cranberry powder with a minimum of $15 \%$ proanthocyanidins were provided by Artemis International (Fort Wayne, IN, USA). Red beet extract containing $30.2 \%$ betanins and approximately $50 \%$ total betalains was provided by FutureCeuticals, Inc. (Momence, IL, USA). Gallotannin and all extracts were stored in light-blocking, airtight packaging in the dark at $-18^{\circ} \mathrm{C}$. Deionized (D.I.) water was used in all dispersion preparation.

\section{Dispersion preparation}

Similar to the dispersion preparation methods described in previous work (Hansen et al. 2021a, b, c), dry WPI or WPI-sucrose blends were first mixed into D.I. water, and aliquots of $50 \%$ gallotannin or extract solutions (gallotannin and extract powders mixed into D.I. water to obtain a $50 \%$ solids content in solution) were subsequently added (when appropriate) and mixed to form 
completed dispersions. As the different bioactives sources had varying bioactives contents, different quantities of extract solutions were required to reach the desired bioactives concentrations in final dispersions; in cases where more extract solution was required, the total quantities of WPI or WPI-sucrose blends added to mixtures were reduced (ratios remained the same) to maintain a constant \% total solids in feeds. A FiveEasy Plus $\mathrm{pH} / \mathrm{mV}$ meter with InLab ${ }^{\bullet}$ Viscous Pro-ISM probe (Mettler Toledo, Hampton, Schwerzenbach, Switzerland) was calibrated at $\mathrm{pH} 4.0$ and 7.0 prior to $\mathrm{pH}$ measurements for dispersions.

Dispersions with eighteen different formulations were prepared three times each for randomized triplicate analysis in a factorial design with four sources of bioactives, three bioactives contents, and two WPI-sucrose ratios (Table 1). Total solids content (35\%), extract/bioactive contents, and WPI-sucrose ratios (1:0 and 1:1) used were determined based on results from previous experiments (Hansen et al. 2020, 2021a, b, c). Dispersions formulated with 1:0 WPI:sucrose had virtually double the WPI and subsequent protein concentrations (ranging from 27 to $34 \%$ protein) compared to those formulated with 1:1 WPI:sucrose (ranging from 14 to $17 \%$ protein), given that all dispersions maintained $35 \%$ total solids contents. Samples were analyzed after a minimum of one hour for defoaming at room temperature.

\section{Feed characterization}

Flow testing

As dispersions were pumped at a constant speed through a benchtop peristaltic pump (120 S/DV, Watson Marlow, Falmouth, England; silicon tubing $85 \mathrm{~cm}$ length, $2 \mathrm{~mm}$ bore, $1 \mathrm{~mm}$ wall, BÜCHI Labortechnik AG, Flawil, Switzerland), the time needed to deposit $10 \mathrm{~mL}$ of dispersion, the mass of $10 \mathrm{~mL}$ of dispersion, individual drop masses, and the number of drops deposited per $1 \mathrm{~min}$ were measured in triplicate, as presented in previous experiments (Hansen et al. 2021a, b, c). Subsequently, feed densities, mass and volume flow rates, and drop surface tensions, diameters, and volumes were calculated from the flow data collected (Hansen et al. 2020, 2021a, b, c).

\section{Particle size distribution}

Particle size distributions were measured in triplicate with methods detailed in earlier studies (Hansen et al. 2021a, b, c) via Malvern Mastersizer 2000 (Malvern Instruments Ltd., Worcestershire, U.K.), adding dispersions dropwise into a Hydro 2000S liquid sampler.

\section{Optical light microscopy}

Diluted dispersions were observed as detailed in previous experiments (Hansen et al. 2021a, b, c), at 40 and 200x magnification, via Nikon Eclipse FN1 optical microscope (Nikon Instruments Inc., Melville, NY, USA)

Table 1 Density and estimated drop diameters from flow tests data and measured diameters (mm) of frozen drops formed from feed dispersions with varied WPI:sucrose, bioactives sources and concentrations, and pH

\begin{tabular}{|c|c|c|c|c|c|c|}
\hline $\begin{array}{l}\text { WPI-sucrose ratio } \\
-\end{array}$ & $\begin{array}{l}\text { Bioactives source } \\
\text { - }\end{array}$ & $\begin{array}{l}\text { [bioactives] } \\
\% \text { w/w }\end{array}$ & $\begin{array}{l}\mathrm{pH} \\
-\end{array}$ & $\begin{array}{l}\text { Density } \\
\mathrm{kg} / \mathrm{m}^{3}\end{array}$ & $\begin{array}{l}\text { Diameter (calculated) } \\
\mathrm{mm}\end{array}$ & $\begin{array}{l}\text { Diameter (frozen) } \\
\mathrm{mm}\end{array}$ \\
\hline $1: 0$ & $n / a$ & 0 & 6.33 & $1062 \pm 9$ & $4.51 \pm 0.02$ & $4.48 \pm 0.11$ \\
\hline $1: 1$ & $\mathrm{n} / \mathrm{a}$ & 0 & 6.22 & $1057 \pm 11$ & $4.54 \pm 0.02^{*}$ & $4.36 \pm 0.13^{*}$ \\
\hline $1: 0$ & Pure gallotannin & 0.5 & 6.20 & $1055 \pm 15$ & $4.58 \pm 0.08$ & $4.52 \pm 0.13$ \\
\hline $1: 1$ & Pure gallotannin & 0.5 & 6.15 & $1055 \pm 6$ & $4.65 \pm 0.02^{*}$ & $4.45 \pm 0.13^{*}$ \\
\hline $1: 0$ & Pure gallotannin & 1 & 6.19 & $1062 \pm 13$ & $4.55 \pm 0.10$ & $4.47 \pm 0.14$ \\
\hline $1: 1$ & Pure gallotannin & 1 & 6.00 & $1061 \pm 13$ & $4.67 \pm 0.04^{*}$ & $4.53 \pm 0.05^{*}$ \\
\hline $1: 0$ & Aronia extract & 0.5 & 6.19 & $1030 \pm 17$ & $4.59 \pm 0.04^{*}$ & $4.50 \pm 0.14$ \\
\hline $1: 1$ & Aronia extract & 0.5 & 6.14 & $1052 \pm 3$ & $4.59 \pm 0.01^{*}$ & $4.51 \pm 0.06^{*}$ \\
\hline $1: 0$ & Aronia extract & 1 & 6.05 & $1042 \pm 17$ & $4.60 \pm 0.02^{*}$ & $4.43 \pm 0.08^{*}$ \\
\hline $1: 1$ & Aronia extract & 1 & 5.81 & $1033 \pm 15$ & $4.64 \pm 0.02^{*}$ & $4.45 \pm 0.07^{*}$ \\
\hline $1: 0$ & Beet extract & 0.5 & 6.17 & $1023 \pm 9$ & $4.59 \pm 0.03$ & $4.52 \pm 0.11$ \\
\hline $1: 1$ & Beet extract & 0.5 & 6.02 & $1038 \pm 10$ & $4.56 \pm 0.03^{*}$ & $4.46 \pm 0.07^{*}$ \\
\hline $1: 0$ & Beet extract & 1 & 6.11 & $1019 \pm 14$ & $4.58 \pm 0.04$ & $4.53 \pm 0.10$ \\
\hline $1: 1$ & Beet extract & 1 & 5.87 & $1038 \pm 11$ & $4.57 \pm 0.02^{*}$ & $4.32 \pm 0.09^{*}$ \\
\hline $1: 0$ & Cranberry extract & 0.5 & 5.95 & $1044 \pm 26$ & $4.67 \pm 0.06^{*}$ & $4.56 \pm 0.10^{*}$ \\
\hline $1: 1$ & Cranberry extract & 0.5 & 5.51 & $837 \pm 179$ & $4.96 \pm 0.37^{*}$ & $4.42 \pm 0.16^{*}$ \\
\hline $1: 0$ & Cranberry extract & 1 & 5.49 & $\mathrm{n} / \mathrm{a}$ & $\mathrm{n} / \mathrm{a}$ & $\mathrm{n} / \mathrm{a}$ \\
\hline 1:1 & Cranberry extract & 1 & 4.96 & $580 \pm 17$ & $5.63 \pm 0.07^{*}$ & $5.91 \pm 0.19^{*}$ \\
\hline
\end{tabular}

*indicates significant differences between calculated and measured diameters 
with Nikon Digital Sight DS-U3 camera control unit (ver. 1).

\section{Viscosity}

Small-strain oscillatory measurement methods detailed in previous experiments (Hansen et al. 2021a, b, c) were modified for triplicate complex viscosity measurements via DHR-2 rheometer (TA Instruments, New Castle, DE, USA). Dispersions were oscillated under $0.2 \%$ strain at 1 $\mathrm{Hz}$ frequency once strain sweeps confirmed that $0.2 \%$ strain was within their linear viscoelastic region (LVR; not shown).

\section{Centrifuge separation}

As detailed in previous work (Hansen et al. 2021a, b, c), small portions $(1.25 \mathrm{~g})$ of seven times diluted dispersions and $1 \%$ solutions made from each source of bioactives were added to $1.5 \mathrm{~mL}$ tubes (graduated with flat caps, Fisherbrand $^{\oplus}$, Fisher Scientific, Hampton, NH, USA), centrifuged at $13,523 \times \mathrm{g}$ and $20^{\circ} \mathrm{C}$ for $20 \mathrm{~min}$ (Centrifuge 5424 R with FA-45-24-11 rotor, Eppendorf, Hamburg, Germany), and subsequently observed.

\section{Frozen drop preparation}

As detailed in earlier studies (Hansen et al. 2021a, b, c), dispersions were deposited dropwise into pans filled with liquid nitrogen $\left(\mathrm{LN}_{2}\right)$ (100\% purity; Airgas, Madison, WI, USA), held for $\sim 5 \mathrm{~min}$ to harden, and diameters were measured immediately upon removal.

\section{Frozen drop diameters}

Digital Vernier calipers (0-150 mm; Stainless Hard) were used to measure the diameters of frozen beads as described in earlier experiments $(n=9)$ (Hansen et al. 2021a, c).

\section{Statistical analysis}

Data from triplicate experiments, analyzed in triplicate $(n=9)$, were used to calculate mean and standard deviation values. Mean values were compared by analysis of variance (2 and 3-way ANOVA; Tukey's HSD test) and independent measures $\mathrm{t}$-tests (equal variance not assumed) performed with $\mathrm{JMP}^{\circ}$ Pro version 15.0.0 (SAS Institute Inc., Cary, NC, USA) when appropriate, with the level of significance determined at $p<0.05$.

\section{Results and discussion}

\section{Feed characterization}

pH

As solution $\mathrm{pH}$ affects protein structures, exposed groups available for intermolecular interactions, and consequent functionality, $\mathrm{pH}$ measurement was a critical analytical tool for comparing the effects of bioactives and extracts on the physico-chemical properties of dispersions with different formulations, as discussed in previous work (Hansen et al. 2021a, b, c). Dispersions containing higher protein contents (1:0 WPI:sucrose ratios) had slightly higher $\mathrm{pH}$ values than those with equal parts protein and sucrose (1:1 WPI:sucrose ratios) (Table 1), likely due to enhanced $\mathrm{pH}$ buffering effects in the system from the additional protein present (Hansen et al. 2021c). In agreement with the results from previous studies (Hansen et al. 2021a, b, c), pH was reduced when dispersions were formulated with increasing bioactives or extract contents. If $\mathrm{pH}$ is reduced so much that values reach the isoelectric point $(\mathrm{pI})$ of proteins (major WPI protein fraction- $\beta$-lactoglobulin, pI $\sim 5.2-5.3$, minor WPI protein fraction- $\alpha$-lactalbumin, $\mathrm{pI} \sim 4.2-$ 4.8 ), protein-protein repulsions are minimized, resulting in aggregation and precipitation that may impact physical properties of dispersions including particle size distribution and viscosity (Kilara \& Harwalkar 1996; Demetriades \& McClements 1998; Song 2009; Coupland 2014; Hansen et al. 2021a, b, c). In the case of pure gallotannin, Aronia berry extract, and beet extract, $\mathrm{pH}$ reductions with increasing bioactives concentrations were unlikely to elicit notable changes in the physical properties of dispersions, as $\mathrm{pH}$ values did not approach the $\mathrm{pI}$ of WPI proteins. Dispersions formulated with cranberry extract showed the most extensive $\mathrm{pH}$ reductions, although only one formulation approached the pI of WPI proteins (1:1 WPI:sucrose, $1 \%$ cranberry PP), with $\mathrm{pH}$ reaching the $\mathrm{pI}$ of $\beta$-lactoglobulin being further reduced. In this case, it is likely that the reduced protein content in the dispersions did not buffer $\mathrm{pH}$ as effectively as higher protein concentrations and may be responsible for some of the aggregation and precipitation observed for dispersions with that formulation, affecting particle size distributions and viscosities measured.

\section{Surface tension and droplet size}

The surface tension forces of a dispersion acting around the circumference of the outlet tubing must be exceeded by the force of gravity pulling on an emerging drop for it to detach, identifying the effect of surface tension on drop size (Hansen et al. 2021a, b, c), with some studies reporting direct relationships between surface tension and drop diameters (Chan et al. 2009; Lee \& Chan 2013). Of the eighteen different dispersion formulations studied, all but one were able to pump under the experimental conditions; dispersions with 1:0 WPI:sucrose and $1 \%$ cranberry extract PP were too viscous to pump and form individual droplets, likely due to extensive interactions occurring in the dispersions at $\mathrm{pH}$ values near protein. As such, flow data could not be obtained for those samples, and multiple separate statistical analyses were required to assess the data collected due to the loss in degrees of freedom from missing data preventing 
analysis of all data together. Additionally, because as all dispersion formulations shared common ' $0 \%$ bioactives' data points, separate statistical analyses were required to qualify trends observed within formulations with the same bioactives source.

Figure 1a depicts the effects of bioactives content (\%) on the surface tensions of dispersions, though effects of WPI:sucrose ratios may also be observed. Data plotted with solid connecting lines (1:1 WPI:sucrose) are often slightly higher than those plotted with dotted connecting lines (1:0 WPI:sucrose), indicating that dispersions containing less WPI and thus less total protein had slightly higher surface tensions than those with more protein. This was observed for samples prepared with pure gallotannin, Aronia extract, and cranberry extract (0.5\% PP), and the two-way ANOVAs and Student's t-tests used to analyze data confirmed that formulations with 1:0 WPI: sucrose ratios had significantly lower $(p<0.05)$ surface tensions than those with 1:1 WPI:sucrose. Dispersions formulated with beet extract did not have significant changes in surface tension with different WPI:sucrose ratios $(p>0.05)$, which can also be observed in Fig. 1a for data with triangle markers. While these results generally make sense, as increasing the protein content in dispersions would likely have greater surface tensionreducing effects (Kitabatake \& Doi 1988), the differences between the mean values for different WPI:sucrose ratios were very slight, indicative of little-to-no meaningful, overall effects on surface tension. Results reported are generally in agreement with the findings from previous experiments, and it is possible that the changes in WPI concentrations of dispersions with 35\% total solids were not strong enough to drive notable changes in surface tension (Hansen et al. 2021a, b, c).

While some data plotted in Fig. 1a show very slightly increasing surface tensions with increasing bioactives concentrations, an increasing trend is most clearly observed for dispersions formulated with 1:1 WPI:sucrose and cranberry extract (circle markers connected by solid lines). The surface tensions of feeds prepared with gallotannin had significantly $(p<0.05)$ higher surface tensions than feeds without bioactives (0\%). Similarly, surface tensions also increased significantly $(p<0.05)$ with increasing Aronia PP concentrations in dispersions. Surface tensions of dispersions also increased significantly $(p<0.05)$ with increasing cranberry PP concentrations, seen clearly in Fig. 1a for data with circle markers. Dispersions containing $1 \%$ bioactives were reported to have significantly higher surface tensions $(p<0.05)$ than those with $0.5 \%$ bioactives, although in this case, the ANOVA was strongly influenced by the data for dispersions with 1:1 WPI:sucrose and cranberry extract, as that is the most clear example in Fig. 1a of a significant increase in surface tension with increasing bioactives concentrations. Interestingly, no significant changes in surface tensions of dispersions were observed with changing beet extract bioactives concentrations $(p>0.05)$, demonstrating the negligible effects of beet extract on the surface tension of dispersions. These findings are also in good agreement with those from earlier work, where dispersions containing WPI experienced increasing surface tensions with increasing Aronia PP concentrations under some conditions, with others exhibiting no meaningful trends (Hansen et al. 2021a, b, c).

Figure 1b displays the average surface tension values of all dispersions containing each respective bioactives source for comparison; cranberry extract was found to impact the surface tensions of dispersions most strongly, giving the highest average surface tension compared to other bioactives sources. The one-way ANOVA used to compare dispersions with 1:0 WPI:sucrose and 0.5\% bioactives confirmed that bioactives source had a significant $(p<0.05)$ effect on surface tension. Tukey's HSD tests specified, showing that dispersions formulated with cranberry extract had significantly higher surface tensions than those formulated with Aronia and beet extracts $(p<0.05)$, but not pure gallotannin $(p>0.05)$. Surface tensions of dispersions with gallotannin were also not significantly different from those with Aronia and beet extracts $(p>0.05)$. Comparing dispersions with 1:1 WPI:sucrose and 0.5 and $1 \%$ bioactives reported that the surface tensions of dispersions with pure gallotannin and Aronia, beet, and cranberry extracts were all significantly different from one another $(p<0.05)$. Dispersions formulated with cranberry extract had the highest surface tensions, followed by pure gallotannin, Aronia extract, and then beet extract, mirroring the data in Fig. $1 b$.

Figure 2 depicts the results of plotting calculated drop diameters against calculated surface tension values derived from flow tests data, and the best fit line applied indicates a strong, direct correlation $\left(R^{2}=0.89\right)$. The one point with notably higher surface tension and a larger diameter represents the 1:1 WPI:sucrose, 1\% cranberry extract PP dispersions, which retained more air than the other formulations after mixing due to its high viscosity stabilizing the foam, thus giving a lower density dispersion to pump and requiring larger drops to form before detaching (Table 1).

\section{Particle size distribution}

Measuring the particle size distributions of dispersions with varying compositions is another way to evaluate the effects of formulation on the physico-chemical properties of dispersions, as compositional changes may induce conformational changes in proteins (Hansen et al. 2021a, b, c). Complex-forming interactions between matrix components (such as proteins and bioactives) may result, 


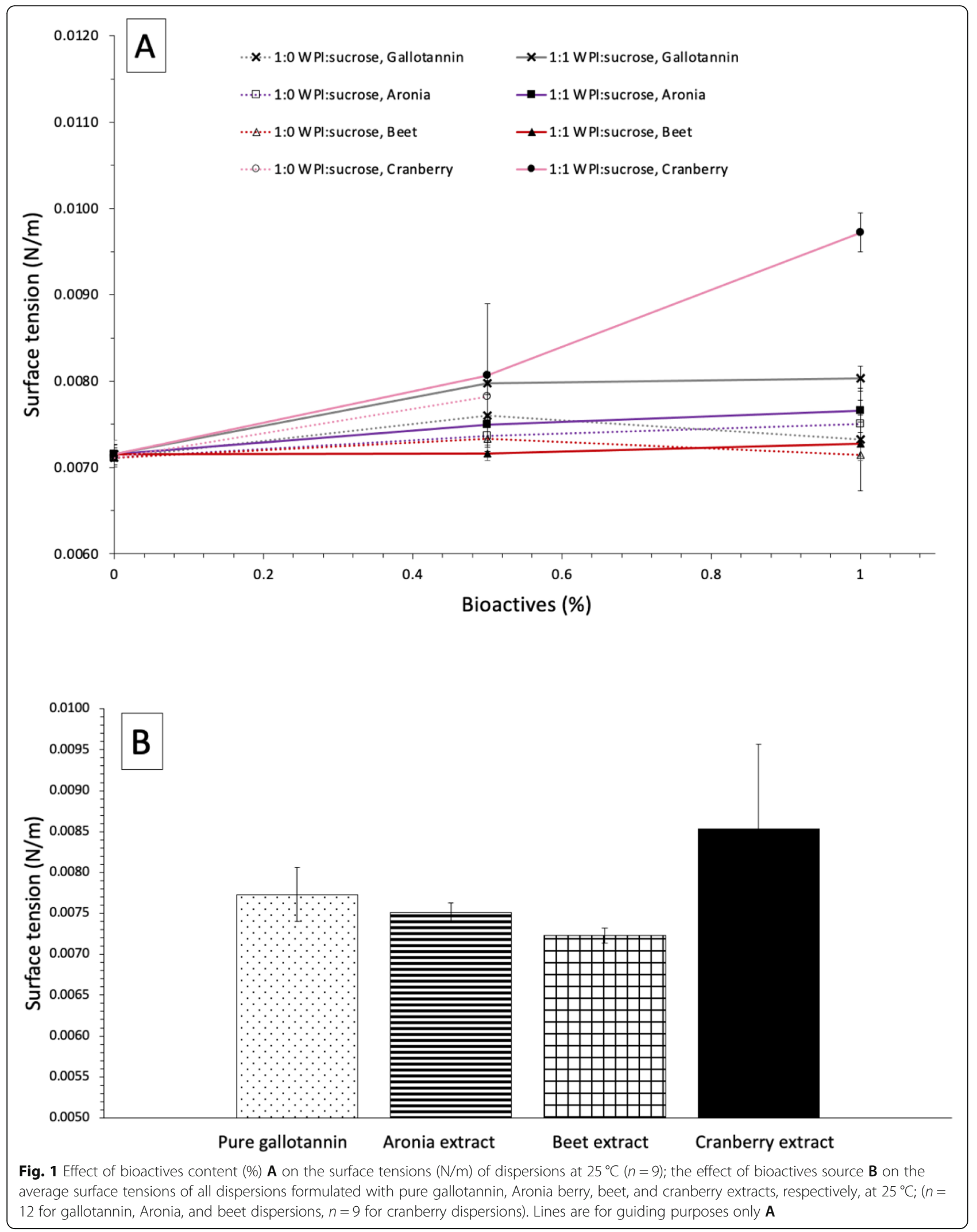




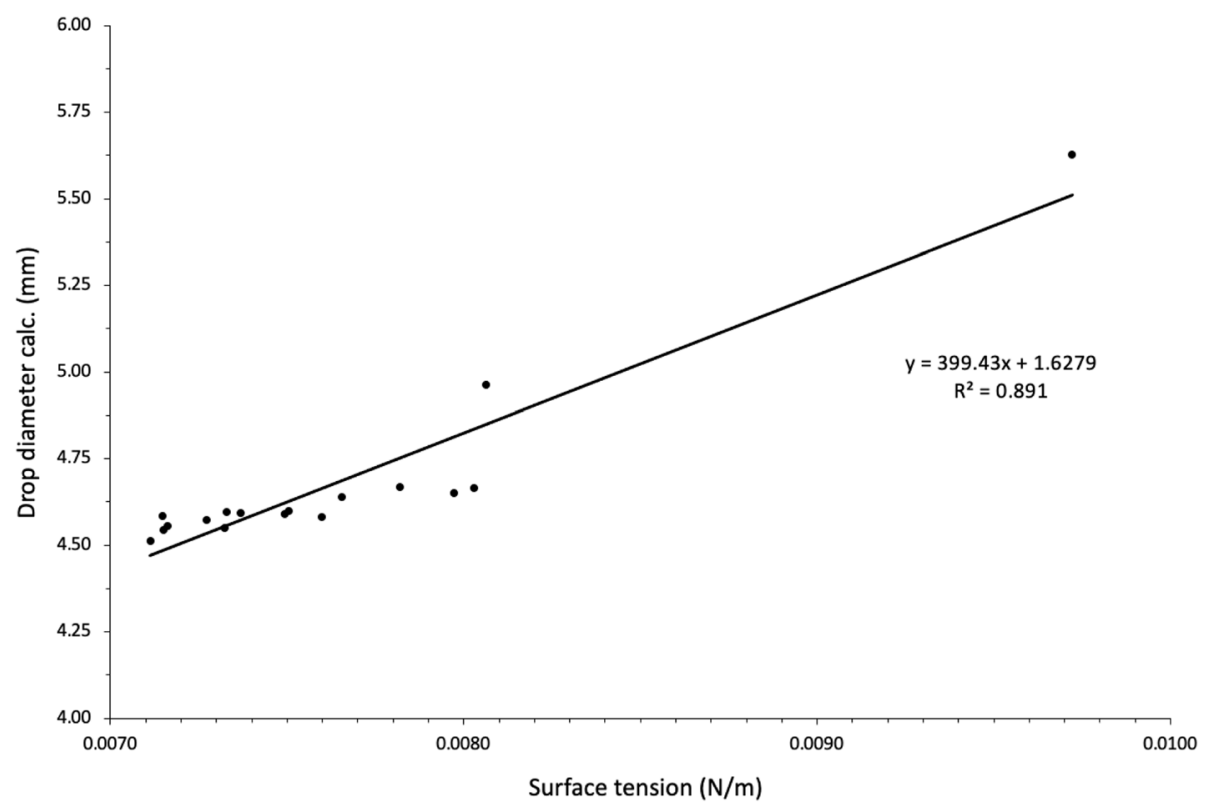

Fig. 2 The relationship between the surface tensions $(\mathrm{N} / \mathrm{m})$ of feed dispersions containing WPI:sucrose ratios of 1:0 and 1:1, bioactives contents of $0,0.5$, and $1 \%$, and bioactives sources including pure gallotannin and Aronia berry, beet, and cranberry extracts at $25^{\circ} \mathrm{C}$, and calculated diameters $(\mathrm{mm})$ of drops

forming aggregates of varied sizes depending on the environmental conditions (Schneider 2016; Hong et al. 2018). While data trends were difficult to distinguish in Fig. 3a, statistical analyses indicated that 1:0 WPI:sucrose dispersions had significantly larger $(p<0.05)$ volume-weighted mean $\left(\mathrm{d}_{4,3}\right)$ particle sizes than 1:1 WPI:sucrose dispersions when Aronia, beet, and cranberry extracts were present. Overall differences in mean values were never more than a few microns, indicating that the changes were very slight. Interestingly, comparison of dispersions formulated with pure gallotannin found that 1:0 WPI:sucrose dispersions had significantly $(p<0.05)$ smaller average particle sizes than dispersions formulated with 1:1 WPI: sucrose ratios. These findings may potentially indicate excesses of protein in the systems for complexation, though optimization was not the focus of this experiment. As a whole, these results are in good agreement with the findings of previous experiments, where the changes in average particle sizes with changing protein:sugar ratios were either insignificant or very small, indicating that sugars were unlikely to affect protein or protein-PP interactions and simply dissolved into solutions (Hansen et al. 2021a, b, c).

Most formulations in Fig. 3a show no notable changes in particle size with changing bioactives concentrations. A minority of the formulations- dispersions containing cranberry extract (circle markers) and dispersions comprised of 1:1 WPI:sucrose with pure gallotannin ( $\mathrm{x}$ markers connected by solid lines)- show increasing particle size trends to differing extents. The two-way ANOVAs and Tukey's HSD tests used to analyze dispersions with pure gallotannin and cranberry extract reported that the average particle sizes of dispersions steadily and significantly $(p<0.05)$ increased with increasing bioactives concentrations at each level of addition. In dispersions with Aronia extract, the only significant increase $(p<0.05)$ occurred between 0.5 and $1 \% \mathrm{PP}$, and the changes in mean sizes were notably smaller (only a few microns). Dispersions containing beet extract underwent no significant changes in particle size with changing bioactives concentrations $(p>0.05)$, in accordance with the results of Martínez et al. (2019), indicating no changes in aggregate sizes upon complexation of betalains with proteins. The three-way ANOVA used to compare all dispersions containing bioactives indicated that particle size increased with increasing bioactives concentrations, despite most formulations (often those containing Aronia and beet extracts) not exhibiting the same extent of change. The increases in particle size data observed for the few formulations containing cranberry extract and 1:1 WPI:sucrose with pure gallotannin in Fig. 3a strongly influenced the ANOVA report to the point where it was not representative of the majority of dispersions examined. These results are in overall agreement with those from earlier works, where changes in average particle sizes of WPI dispersions with changing Aronia PP concentrations were typically slight (only a few microns difference), even when identified as 'significant' 


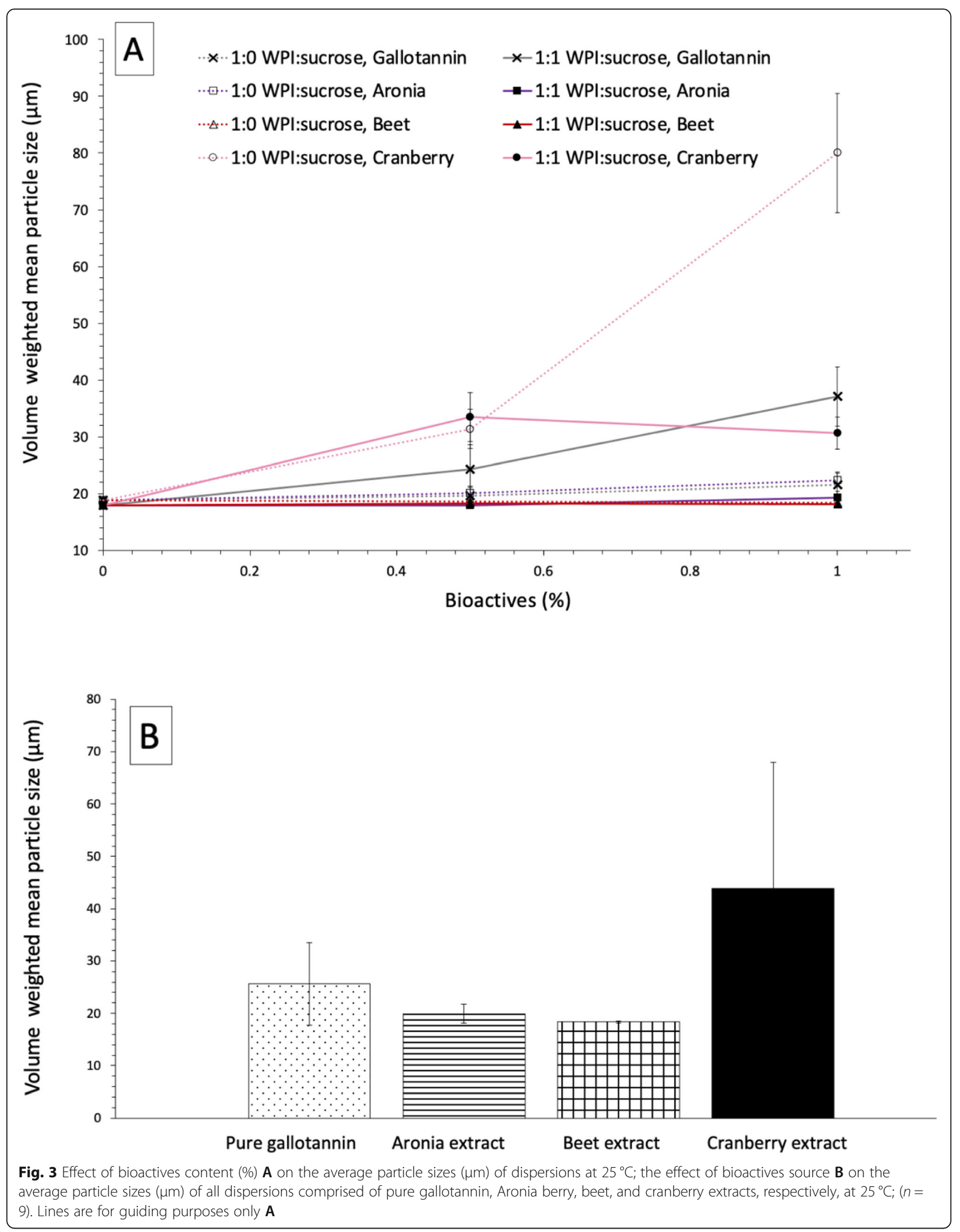


by ANOVA analyses (Hansen et al. 2021a, b, c). Results also align with the observations made when Giloy juice to was added to goat milk, resulting in slightly larger particle sizes in beverages (Sharma et al. 2021).

In Fig. 3b, the average particle size values of all dispersions containing each respective bioactives source may be compared. The three-way ANOVA used to compare dispersions formulated with bioactives reported that bioactives sources had a significant $(p<0.05)$ effect on average particle sizes. Tukey's HSD tests clarified, indicating that dispersions formulated with beet extract had the smallest average particle sizes, followed by Aronia extract, then pure gallotannin, and dispersions with cranberry extract were found to have the largest average particle sizes by far compared to the others (Fig. 3b). Particle sizes of dispersions with Aronia and beet extracts were not found to be significantly different from one another $(p>0.05)$ but were found to be significantly different $(p<0.05)$ from both pure gallotannin and cranberry extract, which were both significantly different from one another $(p<0.05)$. These observations support our hypothesis, that larger polyphenolic compounds (like those in the cranberry extract) would result in greater responses in the functional properties of dispersions.

WPI dispersions have resulted in normal particle size distributions when measured in previous experiments (Hansen et al. 2021a, b, c), with peaks representing unhydrated protein particles remaining in dispersions. Dispersions formulated with pure gallotannin and Aronia extract also exhibited relatively normal distributions (Fig. 4), but with small tails at larger sizes. The major peaks likely continue to represent the unhydrated protein particles remaining in solution but present in slightly smaller volumes; the small tails formed likely include larger sized complexes formed between proteins and bioactives. Dispersions containing beet extract showed virtually no change in particle size distribution compared to WPI dispersions without bioactives, indicating that very little complexation interactions occurred in the system (Fig. 4). Dispersions containing cranberry extract, however, demonstrated very different particle size distributions compared to the other extracts. The distribution was very broad with a peak at larger sizes and a significant, broad shoulder to the left of the peak (likely representative of unhydrated protein particles remaining). Dispersions formulated with cranberry extract exhibited the largest increases in surface tensions and particle sizes of all formulations, demonstrating the extent of strong protein-PP complexation interactions occurring in the system and resulting in large aggregate formation.

Imaging the diluted dispersions with an optical microscope supported the trends observed with Mastersizer particle size measurements, as in previous work (Hansen et al. 2021a, b, c). The significant increases in particle sizes for dispersions formulated with cranberry extract are confirmed in Figs. 5, and 6 supports the Mastersizer data indicating that the largest changes in particle size occurred in formulations containing cranberry extract.

\section{Viscosity}

Small changes in composition can influence the types and volumes of intermolecular interactions that may occur in a system, potentially altering the viscosity of a dispersion and other functional properties as well

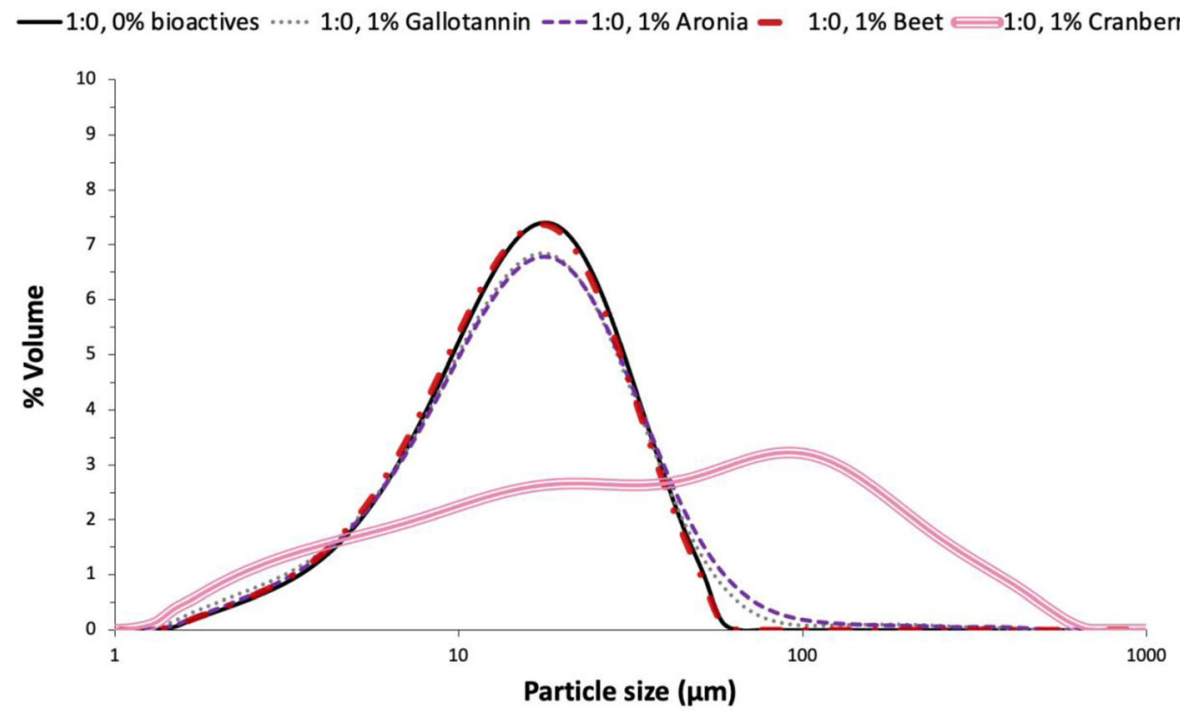

Fig. 4 Particle size distributions of feed dispersions comprised of 1:0 WPl:sucrose ratios with 0\% bioactives and 1\% bioactives from pure gallotannin, Aronia berry, beet, and cranberry extracts at $25^{\circ} \mathrm{C} ;(n=9)$ 

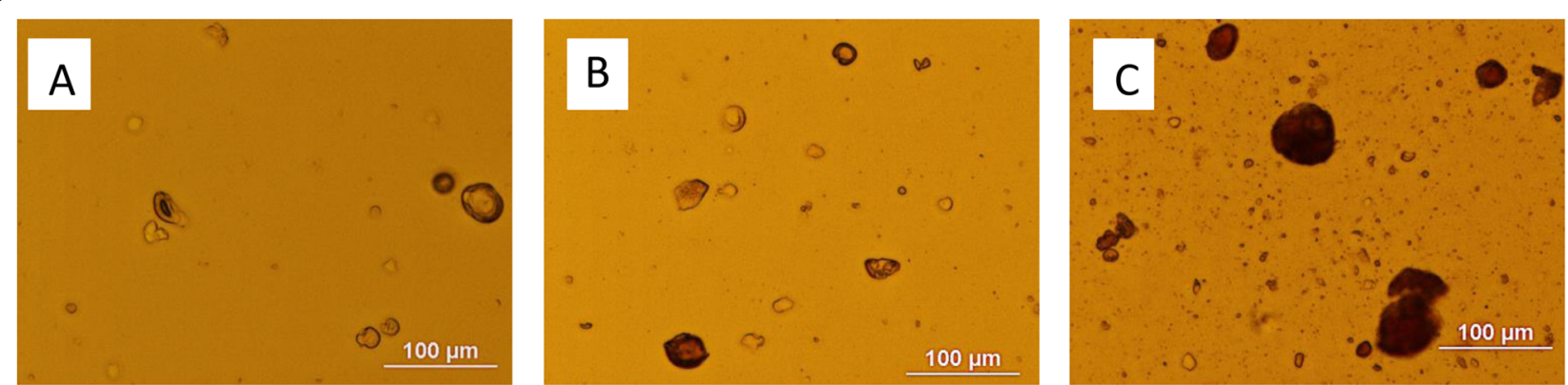

Fig. 5 Optical light microscope images at 200x magnification depicting the microstructures of diluted feed dispersions with 1:0 WPI:sucrose with $0 \%$ bioactives $\mathbf{A}, 0.5 \%$ bioactives $\mathbf{B}$, and $1 \%$ bioactives from cranberry extract $\mathbf{C}$. ${ }^{*}$ COLOR USAGE NECESSARY*

(Hansen et al. 2021a, b, c). In Fig. 7a, viscosity data for dispersions formulated with pure gallotannin and Aronia and beet extracts connected with dotted lines (1:0 WPI: sucrose) were notably higher compared to those connected with solid lines (1:1 WPI:sucrose), indicating that feeds with higher WPI concentrations generally had higher viscosities. Dispersions deviated from this trend slightly when cranberry PP were present, showing that dispersions with 1:1 WPI:sucrose had higher viscosities, but only slightly at $1 \%$ PP. The two-way ANOVAs and student's t-tests used to analyze dispersions prepared with pure gallotannin, Aronia extract, and beet extract reported that 1:0 WPI:sucrose dispersions had significantly $(p<0.05)$ higher viscosities than those formulated with 1:1 WPI:sucrose, as seen in Fig. 7a. The two-way ANOVA and student's t-test used to compare feeds with cranberry extract reported that dispersions with 1:1 WPI:sucrose had significantly higher $(p<0.05)$ viscosities than those with 1:0 WPI:sucrose, as did the 3-way ANOVA and Student's t-test comparing all dispersions containing bioactives. In this case, the ANOVA report was strongly driven by the data for dispersions containing cranberry extract. When cranberry extract was added to dispersions, viscosities increased notably compared to other formulations, but most extremely in the case of 1 : 1 WPI:sucrose dispersions. It is possible that the extreme jump in viscosities of 1:1 WPI:sucrose dispersions with the addition of cranberry could be attributed in
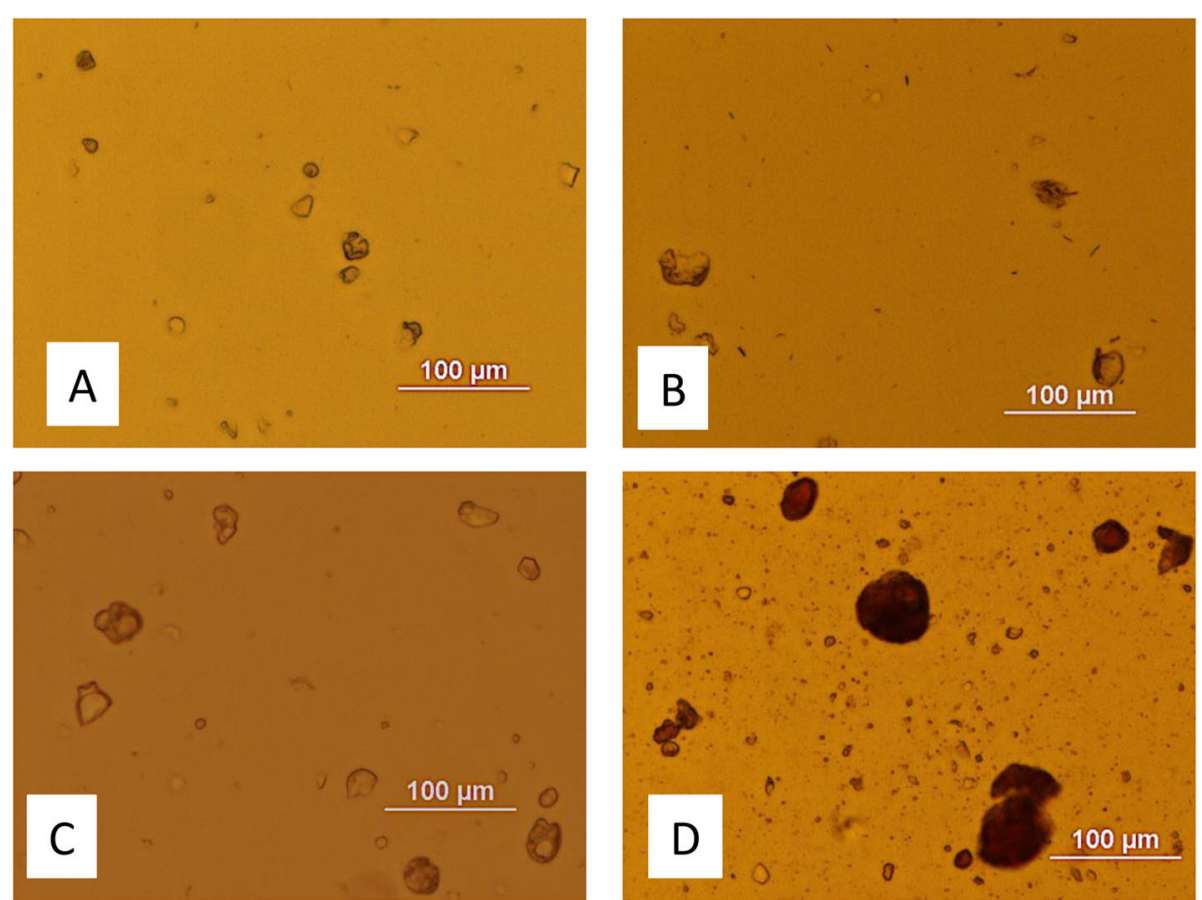

Fig. 6 Optical light microscope images at 200x magnification depicting the microstructures of diluted feed dispersions with 1:0 WPI:sucrose with $1 \%$ bioactives from pure gallotannin $\mathbf{A}$, Aronia berry extract $\mathbf{B}$, beet extract $\mathbf{C}$, and cranberry extract $\mathbf{D}$. ${ }^{*}$ COLOR USAGE NECESSARY* 

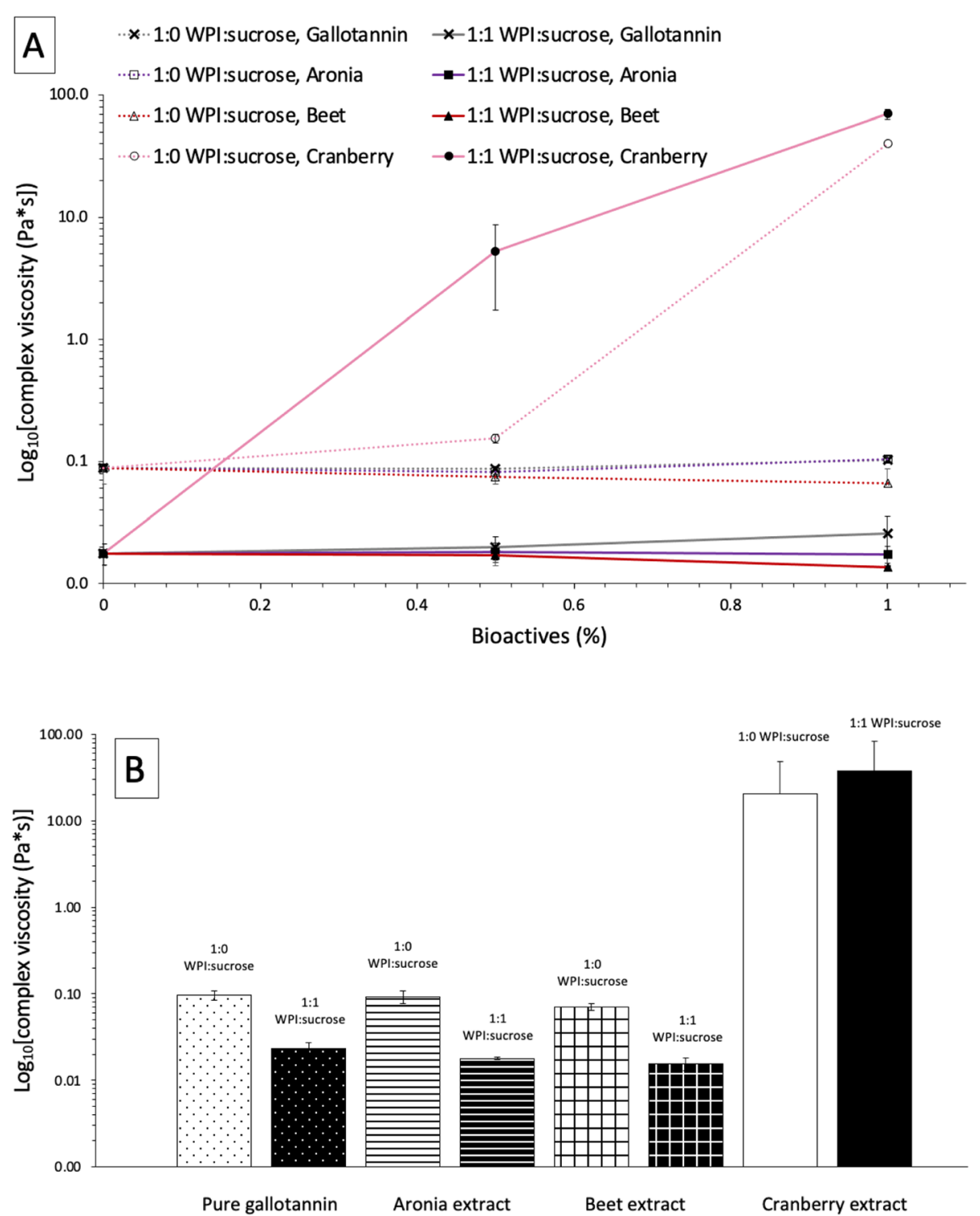

Fig. 7 Effect of bioactives content (\%) A on the complex viscosities ( $\mathrm{Pa}^{*} \mathrm{~s}$ ) of dispersions at $25^{\circ} \mathrm{C}$; the effect of bioactives source $\mathbf{B}$ on the averaged complex viscosities of dispersions comprised of 1:0 and 1:1 WPl:sucrose with pure gallotannin, Aronia berry, beet, and cranberry extracts at 0.5 and $1 \%$ at $25^{\circ} \mathrm{C} ;(n=9)$. Lines are for guiding purposes only $\mathbf{A}$

part to the reduced $\mathrm{pH}$ of feeds to the point of $\mathrm{pI}$ precipitation of aggregates that would increase viscosity in the system, as protein-PP interactions are more abundant near $\mathrm{pI}$, and less protein is present for $\mathrm{pH}$ buffering in the systems. Another possibility is that a synergistic relationship may occur between WPI and cranberry PP at those specific levels of use, thus enhancing complexation interactions present. These findings generally make sense, as previous work has reported that higher protein contents in dispersions resulted in higher viscosities under some conditions (Hansen et al. 2020), though no meaningful trends were observed in many cases (Hansen et al. 2021a, b, c), likely due to an overall weak effect or total solids contents that were too low for detectable shifts.

The only statistically significant $(p<0.05)$ increases in viscosities of dispersions containing gallotannin, Aronia, and cranberry extracts occurred when bioactives concentrations increased from 0.5 to $1 \%$. Interestingly, the complex viscosities of feeds formulated with beet extract were reported to decrease significantly between each level of increasing bioactives concentrations $(p<0.05)$. Changes in viscosities were only clearly observed for dispersions containing cranberry, while changes in feeds with pure gallotannin, Aronia, and beet extracts appeared too slight to be impactful (Fig. 7a). Overall, these 
findings are similar to those reported in previous studies, where increasing Aronia PP contents in dispersions resulted in slight increases in viscosities under some conditions (Hansen et al. 2021b, c), but not all conditions resulted in meaningful trends; similarly, results reported by Sharma et al. (2021) indicated that the addition of Giloy juice (a natural source of polyphenols) to goats milk beverages resulted in increased system viscosities, confirming protein-polyphenol interactions with microscopy.

In Fig. 7b, the average complex viscosity values of dispersions containing each respective bioactives source at 0.5 and $1 \%$ are plotted for comparison at 1:0 and 1:1 WPI:sucrose ratios. Dispersions containing cranberry extract underwent the largest changes in viscosity and had notably higher viscosities compared to dispersions containing the other bioactives sources, which appeared to have similar average viscosities. The three-way ANOVA and corresponding Tukey's HSD test used to analyze dispersions containing bioactives reported that the only bioactives source to significantly increase $(p<0.05)$ the viscosities of dispersions was cranberry extract, while the viscosities of feeds with pure gallotannin, Aronia extract, and beet extract were not significantly different from one another $(p>0.05)$, as seen in Fig. 7b. These findings generally agree with the findings of Girard et al. (2019), where it was found that the viscosities of pastry flour batters containing proteins were relatively unchanged with the addition of monomeric polyphenols (catechins), increased slightly when hydrolyzed tannins (tannic acids) were added, and significantly increased with the addition of condensed tannins (proanthocyanidins). Dispersions formulated with cranberry extract were prepared with slightly less total WPI and sucrose solids due to the need for higher levels of extract addition to reach desired bioactives concentrations and maintain a constant \% total solids. Findings from previous experiments indicated that changes in WPI concentrations in dispersions with similar total solids contents were slight, insinuating that the viscosities of dispersions containing cranberry extract (and thus less WPI solids) may exhibit only minor, if not undetectable, reductions (Hansen et al. 2020). In contrast, dispersions formulated with cranberry extract experienced large increases in the viscosities of their continuous phases likely due to enhanced protein-PP complexation interactions in the system forming larger aggregates when protein pI was approached. Additional complex carbohydrates and oligosaccharides ( $\sim 60 \%$ of the cranberry extract studied) present in the systems at higher cranberry PP concentrations may be a minor contributor to the increased viscosities observed as well (Coleman \& Ferreira 2020). It is likely that the viscosity became so high that the air naturally incorporated into dispersions by the mixing process was stabilized by the continuous phase and large aggregates present, rather than defoaming over time like other dispersions, thus forming something resembling a stabilized foam with significantly lower densities than other dispersions (Table 1), which would have significantly different viscous properties.

\section{Centrifuge separation}

Evaluating dispersions for the formation of colored precipitates and monitoring the relative size of pellets formed after centrifugation can be used as a crude method of identifying the presence of protein-bioactive complexation interactions and aggregate formation (Van Teeling et al. 1971; Hansen et al. 2021a, b, c). Without bioactives present in dispersions, precipitates were white in color and very small, and supernatant was off-white and transparent, as observed in earlier work (Hansen et al. 2021a, b, c); dispersions with pure gallotannin had similar appearances but slightly larger pellets (Fig. 8a). Dispersions containing Aronia extract also had the same appearances as described in previous work (Hansen et al. 2021a, b, c), with deep purple-colored pellets and clear, purple supernatants. Dispersions with cranberry extract had similar appearances, but with slightly larger pellets (Fig. 8); those containing beet extract had pink pellets and deep red,

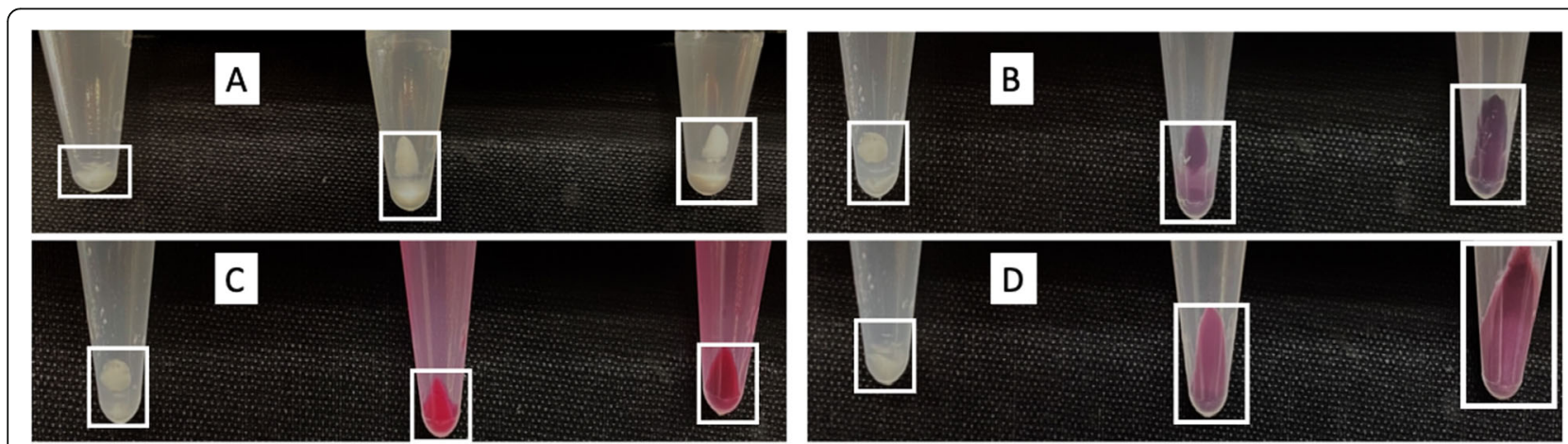

Fig. 8 Image depicting the precipitated fractions (highlighted in boxes) of 7 times diluted, centrifuged dispersions with 1:0 WPI:sucrose and 0\% (Left), 0.5\% (Center), and 1\% bioactives (Right) from pure gallotannin $\mathbf{A}$, Aronia berry extract B, beet extract $\mathbf{C}$, and cranberry extract $\mathbf{D}$. ${ }^{*}$ COLOR USAGE NECESSARY* 
transparent supernatants. Although not pictured, 1:0 WPI: sucrose dispersions generally had larger pellets than 1:1 WPI:sucrose dispersions, likely due to the larger quantity of protein present available for precipitation.

The sizes of pellets formed from centrifuged dispersions generally increased with increasing bioactives concentrations from all sources (Fig. 8). These findings are in agreement with those from earlier studies using Aronia extract (Hansen et al. 2021a, b, c), but to validate that the growing pellet sizes could be attributed to greater quantities of protein-bioactives complexes in dispersions, $1 \%$ bioactives solutions were prepared and centrifuged to determine the amount of precipitate formed at that level of addition (images not shown). No precipitate formed after centrifuging a $1 \%$ gallotannin dispersion, indicative of complete dissolution in D.I. water, and very small, nearly negligible precipitates formed after centrifuging 1\% bioactives solutions with Aronia and beet extracts. Slightly larger pellets formed from centrifuging $1 \%$ cranberry extract PP solutions, though this was expected since more extract was required in the solution to reach the desired $1 \%$ bioactives. This assessment yielded similar findings to previous work (Hansen et al. 2021b), where the minimal precipitation observed after centrifugation of $1 \%$ extract solutions supported claims that the slightly increasing pellet sizes with increasing bioactives concentrations was attributed to increased complex formation. Of the precipitates formed by dispersions of varying composition, those containing gallotannin were typically smallest, likely because the smallest quantity of extract was required to reach the desired bioactives concentrations. Pellets formed from dispersions formulated with beet extract were also small, which may suggest minimal WPIbioactives complexation interactions in the system, as indicated by the other analyses in this study. Dispersions made with Aronia extract had slightly larger pellets, and the largest precipitates were formed from dispersions containing cranberry extract, further indicating more extensive protein-PP interactions in the system (Figs. 8, 9).

\section{Frozen drop characterization Comparison of diameters}

Similar to the findings from earlier work (Hansen et al. 2021c), ten of the seventeen dispersion formulations that were able to undergo flow testing were found to produce frozen beads that had significantly $(p<0.05)$ smaller measured diameters than predicted with calculations (Table 1); this was most likely due to the inadequacy of the correction factor used in calculations of drop diameters to consider the amount of liquid lost upon entering the $\mathrm{LN}_{2}$ bath when small volumes of feeds detach from the main drop upon impact. Only one dispersion formulation produced drops with diameters that were significantly $(p<0.05)$ larger than calculated estimates (1:1 WPI:sucrose, $1 \%$ cranberry extract PP). This phenomenon can be attributed to the notably lower density compared to most of the other dispersions due to the entrapped air that could not defoam due to the highly viscous continuous phase of the matrix (Table 1), thus requiring the drop to grow larger before gravity caused it to detach from the tubing tip. These results give an overall 'success rate' of $35 \%$ for calculations accurately predicting drop diameters, occurring for six of the seventeen dispersion formulations pumped. The one- and two-way ANOVAs and associated Student's t- and Tukey's HSD tests used to compare dispersions reported little-to-no meaningful effects from WPI:sucrose ratios, bioactives concentrations, or bioactives sources on the diameters of drops formed by dispersions. The only exception to these findings was from the Tukey's HSD test used to separately evaluate the effects of bioactives concentrations on drop diameters for dispersions containing 1:1 WPI:sucrose and cranberry extract, where the increase in drop diameters between 0.5 and $1 \%$ cranberry extract PP was considered significant. As already noted, this specific case can likely be attributed to enhanced viscosities and air-holding in the dispersions.

\section{Conclusions}

In these experiments, we aimed to continue our investigation into the effects of bioactives on the physical properties of dispersions containing different WPI:sucrose ratios. Mixing with Aronia berry extract elicited measurable alterations in the viscosities, surface tensions, and particle sizes of dispersions in earlier studies, with changes being attributed to non-covalent protein-PP complexation interactions (Hansen et al. 2021a, b). To build from these findings, we identified a variety of

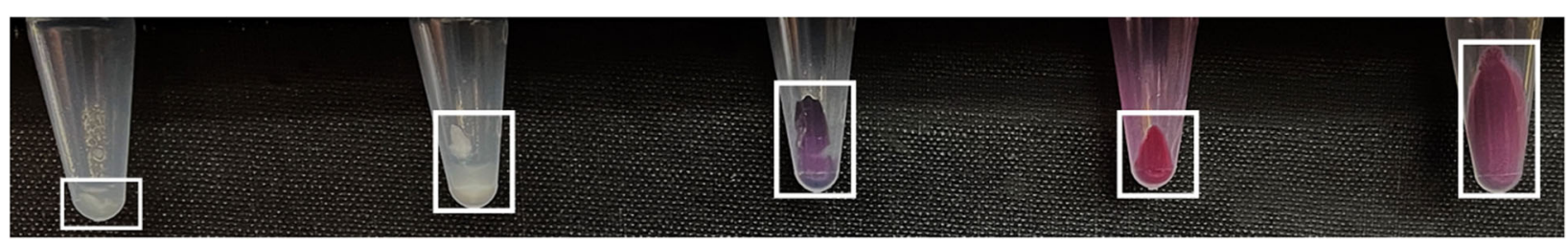

Fig. 9 Image depicting the precipitated fractions (highlighted in boxes) of 7 times diluted, centrifuged dispersions with 1:0 WPI:sucrose and 0\% bioactives (Left) and 1\% bioactives from pure gallotannin (Center, Left), Aronia berry extract (Center), beet extract (Center, Right), and cranberry extract (Left). ${ }^{*}$ COLOR USAGE NECESSARY* 
bioactives sources that possessed diverse structures and sizes for comparison with Aronia extract, including pure gallotannin, beet extract, and cranberry extract. We hypothesized that bioactives/extracts with larger molecular sizes and more hydroxyl groups and hydrophobic regions (such as proanthocyanidins from cranberry extract and pure gallotannin) would be likely to interact more extensively with WPI, which may result in greater measurable changes in physico-chemical properties of dispersions. We observed the largest shifts in the surface tensions, viscosities, and particle size distributions for dispersions formulated with cranberry extract, with the predominant bioactive compound present being proanthocyanidins, condensed tannins that are known to have a high propensity for protein-PP complexation interactions. Dispersions formulated with beet extract, with the predominant bioactive compound present being relatively small-sized betanins, exhibited the least extent of changes in physical properties, likely due to the low relative quantities of hydrophobic regions and hydroxyl groups available for interactions. This work expands on earlier reports, providing more information on the physical effects of adding different bioactive compounds to concentrated WPI dispersions, and continuing the in; .vestigation into the potential for non-covalent proteinbioactive interactions in these feed systems that are ultimately intended for dry bead formation as potential bioactives delivery vehicles (Hansen et al. 2020, 2021c). These findings may inform the formulation and processing stages in the development of functional and nutritional products with high protein contents and natural extracts used as colorants or sources of bioactives, as significant changes in the physical properties due to the addition of relatively low levels of some types of bioactives may compromise desired sensory attributes.

\section{Acknowledgements}

The authors would like to thank the reviewers and Journal Editor for thoughtful reading of the manuscript and constructive comments.

\section{Authors' contributions}

Mackenzie M. Hansen: Conceptualization, Methodology, Validation, Formal analysis, Investigation, Resources, Writing- Original Draft, Writing- Review \& Editing, Visualization, Project administration, Funding acquisition. Richard W. Hartel: Conceptualization, Resources, Writing- Review \& Editing, Visualization, Supervision. Yrjö H. Roos: Conceptualization, Resources, Writing- Review \& Editing, Visualization, Supervision, Funding acquisition. All authors read and approved the final manuscript.

\section{Funding}

Funding for this study was provided by the Lauritzson Foundation via the Lauritzson Research Scholarship, through the College of Science, Engineering and Food Science (SEFS) at University College Cork.

\section{Availability of data and materials}

The datasets used and/or analyzed during the current study are available from the corresponding author on reasonable request.

\section{Declarations}

Ethics approval and consent to participate

Not applicable.

Consent for publication

Not applicable.

\section{Competing interests}

The authors hereby declare no conflict of interest.

Received: 17 November 2021 Accepted: 28 December 2021

Published online: 27 January 2022

\section{References}

Akbar Hussain, E., Sadiq, Z., \& Zia-Ul-Haq, M. (2018). Betalains: Biomolecular aspects. London: Springer International Publishing. https://doi.org/10.1007/ 978-3-319-95624-4.

Baba, W. N., McClements, D. J., \& Maqsood, S. (2021). Whey protein-polyphenol conjugates and complexes: Production, characterization, and applications. Food Chemistry, 365, 130455. https://doi.org/10.1016/j.foodchem.2021.130455.

Banovic, M., Arvola, A., Pennanen, K., Duta, D. E., Brückner-Gühmann, M., Lähteenmäki, L., \& Grunert, K. G. (2018). Foods with increased protein content: A qualitative study on European consumer preferences and perceptions. Appetite, 125, 233-243. https://doi.org/10.1016/j.appet.2018.01. 034.

Calderón-Oliver, M., \& Ponce-Alquicira, E. (2017). Fruits: A source of polyphenols and health benefits. In A. M. Grumezescu, \& A. M. Holban (Eds.), Natural and artificial flavoring agents and dyes, (vol. 7, pp. 189-228). Academic Press. https://doi.org/10.1016/B978-0-12-811518-3.00007-7.

Cao, Y., \& Xiong, Y. L. (2017). Interaction of Whey Proteins with Phenolic Derivatives Under Neutral and Acidic pH Conditions. Journal of Food Science, 82(2), 409-419. https://doi.org/10.1111/1750-3841.13607.

Chan, E.-S., Lee, B.-B, Ravindra, P. \& Poncelet, D. (2009). Prediction models for shape and size of ca-alginate macrobeads produced through extrusiondripping method. Journal of Colloid and Interface Science, 338(1), 63-72. https://doi.org/10.1016/j.jcis.2009.05.027.

Coleman, C. M., \& Ferreira, D. (2020). Oligosaccharides and complex carbohydrates: A new paradigm for cranberry bioactivity. Molecules, 25(4), 881. https://doi.org/10.3390/molecules25040881.

Coupland, J. N. (2014). An introduction to the physical chemistry of food, (illustrated ed. ). Springer Science+ Business Media. https://doi.org/10.1007/978-1-49390761-8.

Dabas, D. (2016). Polyphenols as colorants. Adv Food Technol Nutr Sci Open J, 2(2), S1-S6. https://doi.org/10.17140/AFTNSOJ-SE-2-101.

de Mejia, E. G., Zhang, Q., Penta, K., Eroglu, A., \& Lila, M. A. (2020). The colors of health: Chemistry, bioactivity, and market demand for colorful foods and Natural food sources of colorants. Annual Review of Food Science and Technology, 11(1), 145-182. https://doi.org/10.1146/annurev-food-032519051729.

Demetriades, K., \& McClements, D. J. (1998). Influence of pH and heating on physicochemical properties of whey protein-stabilized emulsions containing a nonionic surfactant. Journal of Agricultural and Food Chemistry, 46(10), 3936-3942. https://doi.org/10.1021/ff980463c.

Gad, A. S., \& El-Salam, M. H. A. (2010). The antioxidant properties of skim milk supplemented with rosemary and green tea extracts in response to pasteurisation, homogenisation and the addition of salts. International Journal of Dairy Technology, 63(3), 349-355. https://doi.org/10.1111/j.1471-03 07.2010.00585.x.

Girard, A. L., \& Awika, J. M. (2020). Effects of edible plant polyphenols on gluten protein functionality and potential applications of polyphenol-gluten interactions. Comprehensive Reviews in Food Science and Food Safety, 19(4), 2164-2199. https://doi.org/10.1111/1541-4337.12572.

Girard, A. L., Castell-Perez, M. E., Bean, S. R., Adrianos, S. L., \& Awika, J. M. (2016). Effect of condensed tannin profile on wheat flour dough rheology. Journal of Agricultural and Food Chemistry, 64(39), 7348-7356. https://doi.org/10.1021/a cs.jafc.6b02601.

Girard, A. L., Teferra, T., \& Awika, J. M. (2019). Effects of condensed vs hydrolysable tannins on gluten film strength and stability. Food Hydrocolloids, 89, 36-43. https://doi.org/10.1016/j.foodhyd.2018.10.018. 
González, S. (2020). Dietary bioactive compounds and human health and disease. Nutrients, 12(2), 348. https://doi.org/10.3390/nu12020348.

Hagerman, A. E. (1989). Chemistry of tannin-protein complexation. In R. W. Hemingway, J. J. Karchesy, \& S. J. Branham (Eds.), Chemistry and significance of condensed tannins, (pp. 323-333). MA: Springer Boston. https://doi.org/10.1 007/978-1-4684-7511-1_20.

Hansen, M. M., Hartel, R. W., \& Roos, Y. H. (2021a). Effects of Aronia polyphenols on the physico-chemical properties of whey, soy, and pea protein isolate dispersions. Food Production, Processing and Nutrition, 3(1), 29. https://doi. org/10.1186/s43014-021-00074-W

Hansen, M. M., Hartel, R. W., \& Roos, Y. H. (2021 b). Encapsulant-bioactives interactions impact on physico-chemical properties of concentrated dispersions. Journal of Food Engineering, 302, 110586. https://doi.org/10.101 6/j.jfoodeng.2021.110586

Hansen, M. M., Hartel, R. W., \& Roos, Y. H. (2021c). Formation of dry beads for bioactives encapsulation by freeze granulation. Journal of Food Engineering, 110847. https://doi.org/10.1016/j.jfoodeng.2021.110847

Hansen, M. M., Maidannyk, V. A., \& Roos, Y. H. (2020). Thermal gelation and hardening of whey protein beads for subsequent dehydration and encapsulation using vitrifying sugars. Journal of Food Engineering, 279, 109966. https://doi.org/10.1016/j.jfoodeng.2020.109966.

Harbertson, J. F., Kilmister, R. L., Kelm, M. A., \& Downey, M. O. (2014). Impact of condensed tannin size as individual and mixed polymers on bovine serum albumin precipitation. Food Chemistry, 160, 16-21. https://doi.org/10.1016/j. foodchem.2014.03.026

Hong, T., Iwashita, K. \& Shiraki, K. (2018). Viscosity control of protein solution by small solutes: A review. Current Protein and Peptide Science, 19(8), 746-758. https://doi.org/10.2174/1389203719666171213114919.

Kapsak, W. R., Rahavi, E. B., Childs, N. M., \& White, C. (2011). Functional foods: Consumer attitudes, perceptions, and behaviors in a growing market. Journal of the American Dietetic Association, 111(6), 804-810. https://doi.org/10.1016/j. jada.2011.04.003.

Kilara, A., \& Harwalkar, V. R. (1996). Denaturation. In Food proteins: Properties and characterization. Wiley- $\mathrm{VCH}$.

Kitabatake, N., \& Doi, E. (1988). Surface tension and Foamability of protein and surfactant solutions. Journal of Food Science, 53(5), 1542-1569. https://doi. org/10.1111/j.1365-2621.1988.tb09319.x.

Lee, B. B., \& Chan, E. S. (2013). Size and shape of calcium alginate beads produced by extrusion dripping. Chemical Engineering and Technology, 36(10), 1627-1642. https://doi.org/10.1002/ceat.201300230.

Li, C., Dai, T., Chen, J., Li, X., Li, T., Liu, C., \& McClements, D. J. (2021). Proteinpolyphenol functional ingredients: The foaming properties of lactoferrin are enhanced by forming complexes with procyanidin. Food Chemistry, 339, 128145. https://doi.org/10.1016/j.foodchem.2020.128145.

Ma, C.-M., \& Zhao, X.-H. (2019). Depicting the non-covalent interaction of whey proteins with Galangin or Genistein using the multi-spectroscopic techniques and molecular docking. Foods, 8(9), 360. https://doi.org/10.3390/ foods 8090360 .

Martínez, J. H., Velázquez, F., Burrieza, H. P., Martínez, K. D., Paula Domínguez Rubio, A., dos Santos Ferreira, C., ... Pérez, O. E. (2019). Betanin loaded nanocarriers based on quinoa seed $11 \mathrm{~S}$ globulin. Impact on the protein structure and antioxidant activity. Food Hydrocolloids, 87, 880-890. https://doi. org/10.1016/j.foodhyd.2018.09.016.

Miguel, M. (2018). Betalains in some species of the Amaranthaceae Family: A review. Antioxidants, 7(4), 53. https://doi.org/10.3390/antiox7040053.

Oliveira, J., Mateus, N., \& de Freitas, V. (2013). Flavanols: Catechins and Proanthocyanidins. In K. G. Ramawat, \& J.-M. Mérillon (Eds.), Natural Products, (pp. 1753-1801). Berlin Heidelberg: Springer. https://doi.org/10.1007/978-3642-22144-6_58.

Quan, T. H., Benjakul, S., Sae-leaw, T., Balange, A. K., \& Maqsood, S. (2019). Proteinpolyphenol conjugates: Antioxidant property, functionalities and their applications. Trends in Food Science and Technology, 91, 507-517. https://doi. org/10.1016/j.tifs.2019.07.049.

Rawel, H. M., Meidtner, K., \& Kroll, J. (2005). Binding of selected phenolic compounds to proteins. Journal of Agricultural and Food Chemistry, 53(10), 4228-4235. https://doi.org/10.1021/jf0480290.

Ropiak, H. M., Lachmann, P., Ramsay, A., Green, R. J., \& Mueller-Harvey, I. (2017). Identification of structural features of condensed tannins that affect protein aggregation. PLoS One, 12(1), e0170768. https://doi.org/10.1371/journal.pone. 0170768 .
Schneider, M. E. (2016). Formation of whey protein-polyphenol aggregates and incorporation into various food structures [PhD food science]. North Carolina State University.

Sęczyk, Ł., Świeca, M., Kapusta, I., \& Gawlik-Dziki, U. (2019). Protein-phenolic interactions as a factor affecting the physicochemical properties of White Bean proteins. Molecules, 24(3), 408. https://doi.org/10.3390/molecules24030408.

Sharma, H., Singh, A. K., Deshwal, G. K., Rao, P. S., \& Kumar, M. D. (2021). Functional Tinospora cordifolia (giloy) based pasteurized goat milk beverage: Impact of milk protein-polyphenol interaction on bioactive compounds, antioxidant activity and microstructure. Food Bioscience, 42, 101101. https://doi. org/10.1016/j.fbio.2021.101101.

Sigurdson, G. T., Tang, P., \& Giusti, M. M. (2017). Natural colorants: Food colorants from Natural sources. Annual Review of Food Science and Technology, 8(1), 261-280. https://doi.org/10.1146/annurev-food-030216-025923.

Song, J. (2009). Insight into "insoluble proteins" with pure water. FEBS Letters, 583(6), 953-959. https://doi.org/10.1016/j.febslet.2009.02.022.

Tsao, R. (2010). Chemistry and biochemistry of dietary polyphenols. Nutrients, 2(12), 1231-1246. https://doi.org/10.3390/nu2121231.

Van Teeling, C. G., Cansfield, P. E., \& Gallop, R. A. (1971). An anthocyanin complex isolated from the syrup of canned blueberries. Journal of Food Science, 36(7), 1061-1063. https://doi.org/10.1111/j.1365-2621.1971.tb03346.X.

Xie, L., Lee, S. G., Vance, T. M., Wang, Y., Kim, B., Lee, J.-Y., ... Bolling, B. W. (2016). Bioavailability of anthocyanins and colonic polyphenol metabolites following consumption of aronia berry extract. Food Chemistry, 211, 860-868. https:// doi.org/10.1016/j.foodchem.2016.05.122.

Xie, L., Vance, T., Kim, B., Lee, S. G., Caceres, C., Wang, Y., ... Bolling, B. W. (2017). Aronia berry polyphenol consumption reduces plasma total and low-density lipoprotein cholesterol in former smokers without lowering biomarkers of inflammation and oxidative stress: A randomized controlled trial. Nutrition Research, 37, 67-77. https://doi.org/10.1016/j.nutres.2016.12.007.

Zhao, H.-S., Ma, Z., \& Jing, P. (2020). Interaction of soy protein isolate fibrils with betalain from red beetroots: Morphology, spectroscopic characteristics and thermal stability. Food Research International, 135, 109289. https://doi.org/10.1 016/j.foodres.2020.109289.

\section{Publisher's Note}

Springer Nature remains neutral with regard to jurisdictional claims in published maps and institutional affiliations.
Ready to submit your research? Choose BMC and benefit from:

- fast, convenient online submission

- thorough peer review by experienced researchers in your field

- rapid publication on acceptance

- support for research data, including large and complex data types

- gold Open Access which fosters wider collaboration and increased citations

- maximum visibility for your research: over $100 \mathrm{M}$ website views per year

At BMC, research is always in progress.

Learn more biomedcentral.com/submissions 